\title{
Characteristics of districts in Pakistan with persistent transmission of wild poliovirus, 2000-2001
}

\author{
S.A. Lowther, ${ }^{1}$ T. Mir, ${ }^{2}$ M.K. Bile, ${ }^{2}$ R. Abdul Hafiz ${ }^{3}$ and A.W. Mounts ${ }^{2}$
}

خصائص المناطق التي تستمر فيها سراية الفيروس البري لثنلل الأطفال في باكستان 2000-2001

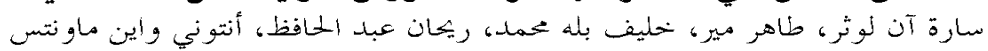

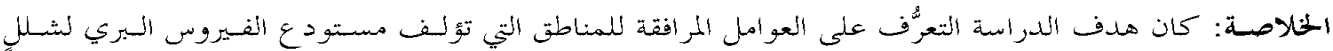

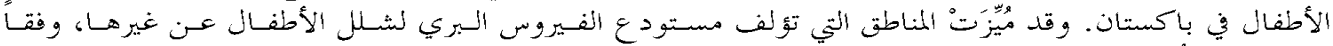

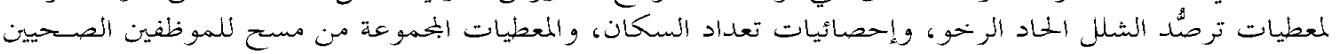

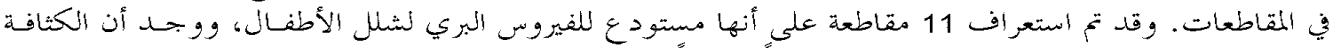

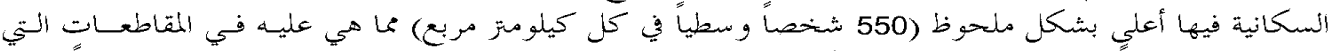

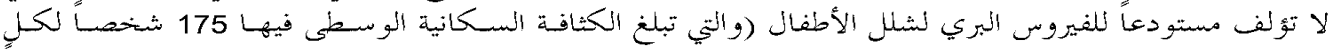

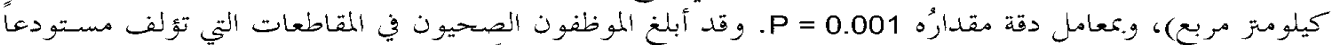

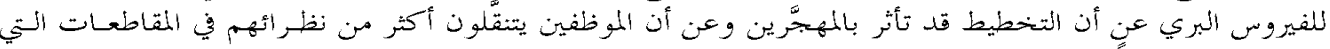

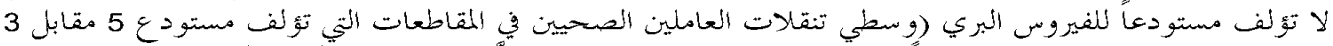

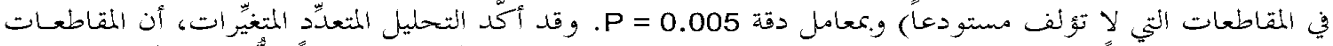

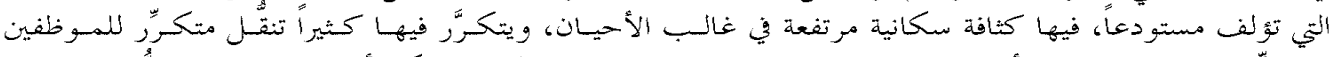

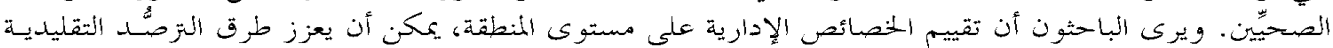

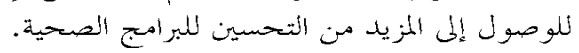

ABSTRACT We sought to identify factors associated with being a reservoir district for wild poliovirus in Pakistan. Differences between reservoir and non-reservoir districts were identified using acute flaccid paralysis surveillance data, population census statistics and data from a survey of district health officials (DHOs). Of the 11 poliovirus reservoir districts identified, population density was significantly higher (median 550 persons $/ \mathrm{km}^{2}$ ) than the nonreservoirs (median 175 persons $/ \mathrm{km}^{2}$ ). DHOs from reservoir districts more often reported that planning was affected by refugees and they had more frequent $\mathrm{DHO}$ transfers compared with non-reservoir districts. Multivariate analysis confirmed that reservoirs more often had high population density and frequent $\mathrm{DHO}$ transfers. Assessment of districtlevel and management characteristics can supplement surveillance methods to further improve health programmes.

Caractéristiques des districts où la transmission du poliovirus sauvage continue au Pakistan, 2000-2001 RÉSUMÉ Nous avons cherché à identifier les facteurs qui font qu'un district est une zone de réservoir du poliovirus sauvage au Pakistan. Les différences entre les districts qui sont ou non une zone de réservoir ont été identifiées en utilisant les données de la surveillance de la paralysie flasque aiguë, les statistiques du recensement de la population et des données tirées d'une enquête des responsables sanitaires de district. Dans les 11 districts identifiés comme étant une zone de réservoir du poliovirus, la densité de population était significativement plus élevée (médiane de 550 personnes $/ \mathrm{km}^{2}$ ) que dans les districts qui ne sont pas des zones de réservoir (médiane de 175 personnes $/ \mathrm{km}^{2}$ ). Les responsables sanitaires des districts qui sont des zones de réservoir signalaient plus souvent que la planification était affectée par les réfugiés et étaient plus fréquemment transférés par rapport aux districts qui ne sont pas une zone de réservoir. L'analyse multivariée a confirmé que les zones de réservoir avaient plus souvent une forte densité de population et dans ces zones, les transferts de responsables sanitaires de district étaient plus fréquents. L'évaluation des caractéristiques de la gestion et au niveau du district peut compléter les méthodes de surveillance traditionnelles pour améliorer davantage les programmes de santé.

${ }^{1}$ World Health Organization, Polio Eradication Initiative, Islamabad, Pakistan (Consultant, 2001).

${ }^{2}$ World Health Organization, Islamabad, Pakistan.

${ }^{3}$ National Institutes of Health, Expanded Programme on Immunization, Islamabad, Pakistan,

Received: 31/03/03; accepted: 14/01/04

البحلة الصحية لشرق المتو سط، منظمة الصحة العالمية، البحلد العاشر، العددان ع-0، ع • • 


\section{Introduction}

Global poliomyelitis incidence has decreased 99\% since the World Health Assembly agreed to instigate the Poliomyelitis Eradication Initiative in 1988 [1]. Pakistan began poliomyelitis eradication activities in 1994 and has had considerable success [2]. These activities are conducted with the ongoing World Health Organization (WHO) Expanded Programme on Immunization (EPI), which seeks to vaccinate children against poliomyelitis, measles, diphtheria, pertussis, tuberculosis, tetanus, and hepatitis B.

Numerous national immunization days (NIDs) have resulted in a considerable decline and localization of cases in Pakistan [2]. However, despite these efforts, several areas in Pakistan appear to be reservoirs where wild poliovirus circulation persists throughout the year, repeatedly reintroducing infection to nearby susceptible populations during the higher transmission season. Presumably a certain threshold of susceptible population would be required to sustain virus circulation in these districts; however, other factors such as effective management of health resources may also be important.

In Pakistan, the administrative tiers of the health system include the federal, provincial and district levels. The federal office is responsible for national health policy decisions, vaccine procurement and distribution of resources to provinces. Provincial health offices are responsible for the administration of health programmes throughout the province, distribution of vaccines and supplies to districts, and supervision and monitoring of district-level activities. Programme implementation, daily management and control of resources are performed at the district level by district health officers (DHOs) (or by agency surgeons in the case of federally administered tribal agencies). In 2000 there were 122 districts-level administrative areas (including 7 tribal agencies).

Areas with continued transmission of wild poliovirus have been examined and identified through ongoing active surveillance [1]. However, no published studies have taken an ecologic approach to examining district-level management characteristics that may affect the success of the administrative area in poliomyelitis eradication. Using acute flaccid paralysis (AFP) surveillance data, we sought to describe the characteristics of districts where there appeared to be persistent wild poliovirus transmission in Pakistan. This study examines the relationship between several characteristics of districts, district health management and the presence of a poliovirus reservoir to identify specific factors that might be modified to improve the effectiveness of poliomyelitis eradication in Pakistan.

\section{Methods}

On February 28, 2001 a national conference on poliomyelitis eradication was held in Islamabad, Pakistan. All 122 DHOs and agency surgeons were asked to attend. (For this study, the designation "DHO" will include both district health officers and agency surgeons.) DHOs were asked to complete a self-administered survey to collect demographic information such as age, sex, educational achievements, training and years of experience. Information on their district health system that might affect health programme planning, such as data on population migration (e.g. refugees or drought-related movement) was collected. The survey was also used as a forum to express opinions (e.g. describe specific

لبحلة الصحية لشرق المثتوسط، منظمة الصحة العلمية، البحلد العاشر، العدذان ع-0، ع • • 
weaknesses or gaps in their district in personnel or supplies). Surveys were later mailed to those DHOs that either did not attend the conference or did not complete the survey at the time of the conference. Because of its nature as a feedback mechanism, the survey was neither anonymous nor confidential, and respondents were informed that the information they provided would be examined to give feedback and assess programme planning with specific regard to their district.

AFP surveillance data reported from 2000 through 2001 were analysed to identify districts with persistent and low transmission season wild poliovirus circulation. Adequacy of surveillance data was assessed using standard surveillance indicators, i.e. rates of non-poliomyelitis AFP (1 case per 100000 population expected), 60day case follow-up (expected to be done on all cases), and adequate stool collection (greater than $80 \%$ of all stool specimens collected met the requirements of 2 stool specimens per case collected at least 24 hours apart, within 14 days of the onset of paralysis, and arriving in the laboratory with intact reverse cold chain and sufficient quantity for analysis). Data on population size, area size and population density were obtained from the Population Census Bureau [3].

\section{Analysis}

Reservoir districts were defined as those districts with wild poliovirus isolated during 5 out of 8 quarters of the years 2000 and 2001 and with virus isolated during low transmission season (December through March) at least one of the years 2000 and 2001.

Several continuous variables were recoded for assessment. For example, because of its broad range among districts, population density was transformed to a logarithmic scale [i.e. In (population density)] and was categorized into 2 levels: high density, defined as $\ln$ (population density) $>$ 7.0 and low density, defined as ln (population density) $\leq 7.0$. The number of DHOs transferred in the past 5 years was also categorized into 2 levels: frequent transfers (more than 4 per 5 years) and less frequent transfers (4 or fewer per 5 years). Univariate analysis was performed using Epi-Info software where differences were examined between poliovirus reservoir districts and non-reservoir districts. The Kruskal-Wallis test was used to compare district-level characteristics whose values were coded as continuous with exact $P$-values reported. Odds ratios (OR) and exact 95\% confidence intervals (95\% CI) were used to compare characteristics coded as categorical. Any factors found to be significantly associated with being a reservoir district from univariate analysis were included in multivariate analysis using SAS (Cary, North Carolina, United States of America) statistical software. For all statistical tests a $P$-level of 0.05 was used as significant.

\section{Results}

\section{Reservoirs for wild poliovirus}

Fifty-nine districts had poliovirus isolated in 2000 and 34 in 2001; 11 administrative districts met our definition of reservoir district. These included Quetta district in Balochistan province; Bannu and Peshawar districts in North-west Frontier Province, Faisalabad district in Punjab province; and Hyderabad, Jacobabad, and Karachi districts in Sindh province (Figure 1). Karachi included 5 administrative districts of Karachi Central, Karachi South, Karachi East, Karachi West and Karachi Malir. As can be 


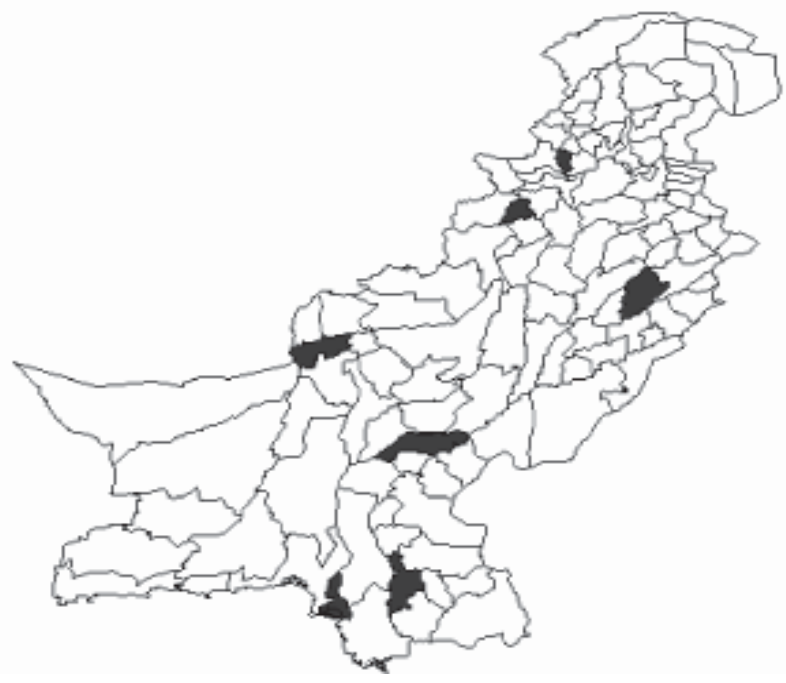

Figure 1 Districts identified from acute flaccid paralysis surveillance to have persistent wild poliovirus transmission in Pakistan during 2000-2001 (defined as districts with wild poliovirus isolated during 5 out of 8 quarters of the years 2000 and 2001 and with the virus isolated during low transmission season (December-March) in at least 1 of the years)

seen from Figure 1, the districts were not clustered together geographically which argues against a single large poliovirus reservoir. Surveillance indicators for 2000 from reservoir districts (rates of non-polio AFP, 60-day follow-up and adequate stool collection) were not significantly different from non-reservoir districts, and met the worldwide standards for such indicators of adequate surveillance (Table 1). Population density was higher among reservoir districts compared with non-reservoir districts (median $=550.7$ versus 175.9 persons per square $\mathrm{km}, P=0.001)$.

\section{Characteristics of DHOs}

In all, 101 DHOs responded to the survey (21 never responded) from all provinces of Pakistan. There were no differences in the DHO response rate by reservoir district status, AFP surveillance characteristics, geographic location/province, or population density. The median age of respondents was 50 years (range 40-60 years) and all DHOs were male. All DHOs were physicians (MBBS) and $46 \%$ had a public health degree or diploma; $10 \%$ reported receiving management training in the past 3 years. In addition, 97\% reported having assigned a specific person to be responsible for EPI. As regards the complications of health programme planning, $90 \%$ of DHOs reported seasonal migration as a complication, 51\% cited refugees $36 \%$ cited drought-related migration, $11 \%$ cited nomads or gypsies, $4 \%$ cited other complications including tribal clashes, border or line-of-control conflict, or smuggling routes. About $16 \%$ reported having a private practice. Prior experience as a DHO was reported by $49 \%$ of respondents with a median of 6 years of experience (range 0 27 years). In the past 5 years, $59 \%$ of

بلملة الصحية لشرق المتو سط، منظمة الصحة العالمية، البحلد العاشر، العدذان ع-0، ع • • 
Table 1 Characteristics among districts and district health officials comparing wild poliovirus reservoir districts to non-reservoir districts, Pakistan, 2000-2001

\begin{tabular}{|c|c|c|c|c|c|c|}
\hline \multirow{2}{*}{$\begin{array}{l}\text { Characteristics } \\
\text { Continuous variables }\end{array}$} & \multicolumn{2}{|c|}{$\begin{array}{l}\text { Reservoir } \\
\text { district }\end{array}$} & \multicolumn{2}{|c|}{$\begin{array}{l}\text { Non-reservoir } \\
\text { district }\end{array}$} & \multicolumn{2}{|c|}{ Statistical analysis } \\
\hline & & Median & Media & & $\begin{array}{l}\text { Kruskal- } \\
\text { Wallis }\end{array}$ & $P$-value ${ }^{a}$ \\
\hline \multicolumn{7}{|l|}{ Surveillance indicators } \\
\hline No. poliomyelitis cases 2001 & & 3.5 & \multicolumn{2}{|c|}{0.0} & 32.70 & 0.000 \\
\hline \multirow{2}{*}{\multicolumn{2}{|c|}{$\begin{array}{l}\text { Non-poliomyelitis AFP rate ( } 1.00 \text { expected) } \\
\text { Non-poliomyelitis enterovirus rate }\end{array}$}} & 1.95 & \multicolumn{2}{|c|}{1.42} & 2.75 & 0.097 \\
\hline & & & \multirow{2}{*}{\multicolumn{2}{|c|}{47}} & & \\
\hline$(0.10$ expected $)$ & & 0.15 & & & 0.16 & 0.690 \\
\hline $\begin{array}{l}\text { Percentage with 60-day follow-up } \\
\text { Percentage with adequate stool }\end{array}$ & & 100 & \multicolumn{2}{|c|}{100} & 0.25 & 0.617 \\
\hline collection & \multicolumn{2}{|r|}{74} & \multicolumn{2}{|l|}{71} & 0.02 & 0.892 \\
\hline \multicolumn{7}{|l|}{ District-level characteristics } \\
\hline Population density (persons per $\mathrm{km}^{2}$ ) & \multicolumn{2}{|c|}{550.7} & \multicolumn{2}{|l|}{175.9} & 13.1 & 0.001 \\
\hline Area size $\left(\mathrm{km}^{2}\right)$ & \multicolumn{2}{|c|}{2268} & \multicolumn{2}{|l|}{5286} & 6.80 & 0.009 \\
\hline Population size & \multicolumn{2}{|c|}{1724915} & \multirow{2}{*}{\multicolumn{2}{|c|}{805235}} & 6.99 & 0.008 \\
\hline Total district health officers in last & & & & & & \\
\hline 5 years & & 5 & \multicolumn{2}{|l|}{3} & 7.73 & 0.005 \\
\hline Categorical variables & No. & $\%$ & No. & $\%$ & $\begin{array}{l}\text { Odds } \\
\text { ratio }\end{array}$ & $95 \% \mathrm{Cl}^{\mathrm{a}}$ \\
\hline \multicolumn{7}{|l|}{ District-level characteristics } \\
\hline Log (population density) > 7.0 & 3 & 33 & 1 & 1 & 45.5 & $4.1-506.2$ \\
\hline $\begin{array}{l}\log \text { (population density) } \leq 7.0 \\
5 \text { to } 8 \text { district health officers per } 5\end{array}$ & 6 & 67 & 91 & 99 & 1 & - \\
\hline $\begin{array}{l}\text { years } \\
\leq 5 \text { district health officers per } 5\end{array}$ & 6 & 67 & 20 & 22 & 7.2 & $1.7-31.4$ \\
\hline years & 3 & 33 & 72 & 88 & 1 & - \\
\hline \multicolumn{7}{|l|}{ District health officer characteristics } \\
\hline $\begin{array}{l}\text { Respondents } \\
\text { Previous experience as district }\end{array}$ & $9 / 11$ & 82 & $101 / 111$ & 91 & 0.98 & $0.2-9.5$ \\
\hline health officer & $6 / 9$ & 67 & $42 / 93$ & 45 & 2.38 & $0.6-10.1$ \\
\hline Has private practice & $0 / 9$ & 0 & $16 / 96$ & 17 & Undef & - \\
\hline $\begin{array}{l}\text { Has public health degree } \\
\text { Specific person assigned to manage }\end{array}$ & $2 / 9$ & 22 & $44 / 94$ & 47 & 0.3 & $0.1-1.6$ \\
\hline $\begin{array}{l}\text { EPI } \\
\text { Had management training in last } 5\end{array}$ & $9 / 9$ & 100 & $89 / 92$ & 97 & Undef & - \\
\hline years & $0 / 9$ & 0 & $10 / 91$ & 11 & Undef & - \\
\hline Reports drought affects district & $3 / 9$ & 33 & $31 / 89$ & 35 & 0.92 & $0.2-3.9$ \\
\hline Reports refugees affect district & $8 / 9$ & 89 & $43 / 91$ & 47 & 8.74 & $1.1-72.8$ \\
\hline $\begin{array}{l}\text { Reports seasonal migration affects } \\
\text { district }\end{array}$ & $8 / 9$ & 89 & $89 / 92$ & 97 & 0.88 & $0.10-7.8$ \\
\hline
\end{tabular}

${ }^{a}$ Exact $\mathrm{P}$-value and $95 \%$ confidence intervals (Cl) are given. A P-level of 0.05 and $95 \% \mathrm{Cl}$ excluding 1.0 was considered statistically significant.

$A F P=$ acute flaccid paralysis. EPI $=$ Expanded Programme on Immunization.

بلملة الصحية لشرق المتوسط، منظمة الصحة العالمية، البجلد العاشر، العددان ع-0، ع • •؟ 
DHOs reported 2 or 3 transfers, with $20 \%$ reporting zero or 1 transfer and $21 \%$ reporting 4 to 7 transfers.

In univariate analysis, several differences were identified between reservoir and non-reservoir districts (Table 1) among characteristics of DHOs and districts. There was no difference in DHO response rate between reservoir and non-reservoir districts (82\% versus $92 \%$ respectively, $P$ $=0.97$ ). DHOs from reservoir districts were more likely to report that problems in health programme planning were affected by refugees $(\mathrm{OR}=8.74, P=0.02)$ but were equally likely as non-reservoir DHOs to report that problems in planning were affected by factors such as drought or seasonal movement. DHOs from reservoir and non-reservoir districts did not differ by educational status, additional public health training, or years of experience. DHOs reported that reservoir districts had significantly more DHOs in the last 5 years compared with non-reservoir districts (median $=5$ versus 3 DHOs, $P=0.005$ ).

Multivariate analysis included 2 districtlevel characteristics (population density and frequency of DHO transfers) and 1 DHO characteristic (reporting that refugees affected health programme planning). This analysis indicated that reservoir districts were more likely to be those among districts of high population density [ $\ln ($ population density) $>7.0]$ (adjusted $\mathrm{aOR}=28.1,95 \%$ CI: 2.2-361.0) and districts with frequent DHO transfers $(>4$ DHO transfers in the last 5 years) $(\mathrm{aOR}=$ 5.1, 95\% CI: 1.03-25.5). However, after controlling for population density and frequency of DHO transfers, DHOs reporting that refugees affected programme planning was no longer significantly associated with reservoir district status.

\section{Discussion}

This analysis describes characteristics of districts and their DHOs in Pakistan with persistent transmission of wild poliovirus, and considers the effect of management and administration on the outcomes of a disease eradication programme. Our data showed that districts with less frequent change of managers were less likely to be poliovirus reservoirs than those with frequent turnover, indicating that consistency of management may improve the outcome of poliomyelitis eradication activities in a given district. Other characteristics of the DHO, such as previous experience as a DHO, management training or total years of experience, were not associated with poliovirus reservoir status. DHOs in the Pakistan health care system are the primary managers of all national public health programmes and are key individuals responsible for a programme's success. Some examples of the responsibilities of DHOs in regard to poliomyelitis eradication planning include: supervising and monitoring of district logistical and personnel planning, disbursement of financial resources and communication with local authorities for involvement.

Our analysis also demonstrated that reservoir districts were more likely to be among districts with the highest population density. This finding is consistent with evidence that urban areas with increased population density are high-risk poliovirus reservoirs [4]. In addition, our analysis illustrates the process of identifying reservoir districts based on natural seasonality of the virus in Pakistan. We believe this method helped improve the effectiveness of immunization campaigns by allowing the concentration of resources in areas needing

لبحلة الصحية لشرق المثتوسط، منظمة الصحة العلمية، البحلد العاشر، العدذان ع-0، ع • • 
additional support; it continues to be an important step in the final stages of poliomyelitis eradication.

Our data also suggest that the presence of a substantial refugee population may affect the success of poliomyelitis eradication at the district level. This is consistent with supplementary individual-level epidemiological data collected during 2001 which indicated that Afghan refugees were at higher risk of poliomyelitis in Pakistan [2]. The additional population may burden a health programmes' allocation of resources as well as increase virus transmission because of a raised population density. Continued attention to identifying high-risk groups will be invaluable as has been illustrated in outbreak situations [5,6].

Previous studies have shown why individual children were under-vaccinated thereby creating reservoirs for wild poliovirus $[7,8]$. However our study is the first to examine risk factors for district and management characteristics of these reservoirs. In Pakistan during 1994, children missed during NIDs were also those more likely to have been unvaccinated or partially-immunized through routine immunization services [9]. Elsewhere, risk factors for children missed during NIDs included failure to be reached by methods of social mobilization, increased distance to NID site [10], lower parental literacy or educational status [2], and age 0-6 months [11]. All polio vaccination campaigns in Pakistan have been house-to-house since 1998 [12] because they have been found to be more complete in coverage and cost-effective. While the house-to-house strategy is shown consistently to improve coverage, published studies to describe reasons why children are missed during house-to-house coverage are lacking. House-to-house immunization campaigns are a massive undertaking which involve considerable planning and more complex logistics on multiple administrative levels. It is therefore conceivable that quality and consistency of programme administration and management may play a greater role in the successful outcomes of eradication activities.

Our assessment makes no attempt to explain all the reasons for the continued transmission of poliovirus in Pakistan. In the recent past, poliomyelitis cases in Pakistan have been un- or under-vaccinated through routine immunization [8]. Routine immunization coverage data could not be validated for the time period of study for every district, and complete, validated countrywide district-specific NID coverage estimations were not available.

The relationship between population density, management turnover rate and poliovirus reservoir may be complex. While a certain population density is necessary to sustain poliovirus circulation, it may also be that densely populated areas, particularly urban areas, may be more desirable posts resulting in more frequent transfer of staff. Alternatively, DHOs in densely populated urban areas may have more difficulties in meeting expected performance standards. Other factors, such as a district literacy rates, socioeconomic status, or per capita health programme funding, may help to describe areas having barriers to successful health programme outcomes. Because of its exploratory nature, our questionnaire did not capture specific reasons for DHO transfer. However, our analysis did identify DHO transfer to be associated with district reservoir status with no association found among factors such as total years of experience, previous experience as a DHO, and training or certification in management. Further assessment of district management may be warranted, both in performance expectations and achievements.

البحلة الصحية لشرق المتو سط، منظمة الصحة العالمية، البحلد العاشر، العددان ع-0، ع + • 
This analysis identifies a management factor that may have an impact on the success of a high-priority disease eradication programme. Our data suggest that decreasing the frequency of transfers in district management may improve the quality of programme implementation. As a result of this study, the United Nations Children's Fund (UNICEF) and WHO have now placed district support teams, comprised of individuals with varying skills, to work directly under the district managers and support all poliomyelitis- and EPI-related activities. These teams receive technical supervision from international and national consultants from the 2 United Nations agencies who are assigned to high-risk districts for periods of up to 1 year and provide additional programme support and continuity.

During both 2002 and 2003 Pakistan conducted 4 rounds of NIDs and 4 rounds of sub-NIDs, which are targeted at areas with factors (such as those described in our analysis) that indicate a high risk for continuing virus transmission [13]. In addi- tion, Pakistan introduced wide- scale independent monitoring of coverage through third-party survey companies to improve the quality of supplementary immunization activities by immediately identifying and vaccinating children initially missed during NIDs.

In conclusion, our analysis has identified DHO transfer rate and population density as important determinants of poliomyelitis eradication success. These aspects are now being addressed along with other critical factors to improve efforts to stop transmission of wild poliovirus. We beleive that the findings described in our paper have implications beyond poliomyelitis eradication and should be considered in other disease control programmes.

\section{Acknowledgements}

We would like to thank Mr Abid Sheik for his administrative assistance in survey collection, and Alex and Samantha Rowe for their critical review of the manuscript.

\section{References}

1. Progress toward global eradication of poliomyelitis, 2001. Morbidity and mortality weekly report, 2002, 51:253-6.

2. Progress toward poliomyelitis eradication-Pakistan and Afghanistan, January 2000-April 2002. Morbidity and mortality weekly report, 51(24):523-4.

3. 1998 census report of Pakistan. Islamabad, Population Census Organization, Statistics Division, Government of Pakistan, 1999.

4. Hull HF et al. Paralytic poliomyelitis: seasoned strategies, disappearing disease. Lancet, 1994, 343:1331-7.
5. Aylward RB et al. Unimmunized gypsy populations and implications for eradication of poliomyelitis in Europe. Journal of infectious diseases, 1997, 175 (suppl. 1):S86-8.

6. Reichler MR et al. Outbreak of paralytic poliomyelitis in a highly immunized population in Jordan. Journal of infectious diseases, 1997, 175(suppl. 1): S62-70.

7. Hennessey KA et al. Widespread paraIytic poliomyelitis in Pakistan: a casecontrol study to determine risk factors and implications for poliomyelitis eradi-

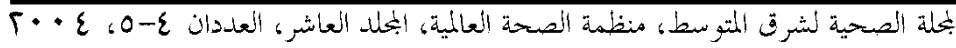


cation. Journal of infectious diseases, 2000, 182(1):6-11.

8. Hennessey KA et al. Widespread paralytic poliomyelitis in Pakistan: a casecontrol study to determine risk factors and implications for poliomyelitis eradication. Journal of infectious diseases, 2000, 182(1):6-11.

9. Reichler MR et al. Evaluation of oral poliovirus vaccine delivery during the 1994 national immunization days in Pakistan. Journal of infectious diseases, 1997, 175(suppl. 1):S205-9.

10. Reichler MR et al. Cluster survey evaluation of coverage and risk factors for failure to be immunized during the 1995 national immunization days in Egypt. In- ternational journal of epidemiology, 1998, 27(6):1083-9.

11. Singh $B$ et al. Pulse polio immunization in Delhi-1995-96: a survey. Indian journal of pediatrics, 1997, 64(1):57-64.

12. Linkins RW et al. Evaluation of house-tohouse versus fixed-site oral poliovirus vaccine delivery strategies in a mass immunization campaign in Egypt. Bulletin of the World Health Organization, 1995, 73(5):589-95.

13. Progress toward poliomyelitis eradication-Afghanistan and Pakistan, January 2002-May 2003. Morbidity and mortality weekly report, 2003, 52(29): 683-5.

\section{Poliomyelitis eradication in the Eastern Mediterranean Region}

Rapid and significant progress towards the eradication of poliomyelitis is continuing in all countries of the Eastern Mediterranean Region. Poliovirus transmission has been interrupted in 17 countries of the Region for more than 3 years. Comprehensive information about the poliomyelitis eradication programme in the Eastern Mediterranean Region can be found at: http://www.emro.who.int/polio/

البحلة الصحية لشرق المتو سط، منظمة الصحة العالمية، البحلد العاشر، العددان ع-0، ع • • 